\title{
Celebrating the birthday of our intellectual common ancestor
}

This month we celebrate the birth of a man with an idea that fundamentally changed the world and how we perceive our place in it. Only the rarest of ideas ripple far from their origins, but those of evolution quickly broke the boundaries of science and touched every aspect of the human condition. This has been to the enrichment as well as consternation of many: poets, philosophers, and theologians no less than biologists must take his ideas into account when plying their trades.

As geneticists, we hold a special place among those who owe tribute to Charles Darwin. Indeed, it was Darwin who, in 1859, first used the term "genetics" in a biological context. ${ }^{1}$ This is fitting in that the links between evolutionary theory and genetics are profound. Modern genetics is informed at every turn by evolutionary considerations and, in turn, provides spectacular confirmation of Darwin's theory. It is no exaggeration to say that our entire field is a grand fulfillment of predictions made in the Origin of Species. I never cease to find pleasure in imagining the delight that Darwin would have experienced were he to survey the modern field of genetics.

When Darwin died in 1882, there were two predications that he knew must eventually be fulfilled if his theory was to stand. The first concerned the age of the earth. He realized early on that the evolution of "endless forms most beautiful and most wonderful" required vast reaches of time almost unimaginable by a citizen of the 19th century (or of the 21st century for that matter). However, his theory's need for deep time was undermined by Lord Kelvin's calculation that the earth was, at most, 40 million years old. Of course, Kelvin did not know about radioactivity, and as the sciences of physics and geology soldiered on, the age of the earth was gradually pushed back to billions of years, ample time for evolution of life's complexity.

The other outstanding issue of vital centrality to Darwin's theory but utterly mysterious during his life was the mechanism of biological inheritance. Darwin (and most of the rest of the world) didn't know that Gregor Mendel had begun to make significant inroads into this puzzle during his own lifetime. Be that as it may, Darwin realized that the mechanism of inheritance must have certain attributes or his theory would fail. It is a stunning triumph of his theory that the implicit predictions regarding heredity in the Origin of Species have been resoundingly fulfilled. It is in this sense that we geneticists are both the great vindicators of Darwin's theory and its greatest benefactors.

The process of evolution by natural selection mandated that biological inheritance must demonstrate underlying variability (the raw substrate of natural selection), mutability (the fodder for differentiation and ultimately speciation), and particulate inheritance. This last point was most contentious at the time of Darwin's death. Contemporary theories of inheritance (fittingly disregarding Mendel) posited a blending of traits in offspring and, as such, were incompatible with the emergence of new forms that would then be able to propagate without being diluted out of existence in the population. The discovery of the gene as a discrete packet of information was precisely compatible with (and necessary for the survival of) Darwin's theory. It is a remarkable testament to modern genetics that we can literally hold in our hand the unit of inheritance and the fundamental unit of natural selection ... and that they are one in the same.

Another oft-overlooked prediction implicit to Darwin's theories of the 19th century hinges on the fact that Darwin, in biology as in geology, was a gradualist. His theory implied that many generations were required to produce the biological complexity that we see around us and that evolution rarely proceeds by great leaps. Implicit in this prediction was that the mechanisms underlying heredity would also need to allow for extraordinarily subtle change. The digital code glimpsed in 1953 by Watson and Crick and broken by Marshall Nirenberg's group in the next decade is precisely such a mechanism. Yes, the unit of selection (the gene) is particulate, but in an additional layer of subtlety, the gene itself is composed of digital constituents-nucleotides-that are in themselves particulate. Thus, unimaginably minor (that is, unimaginable to minds that evolved to consider only rather short time spans) alterations can have persistent small phenotypic impacts that are not lost by "blending" and are visible to the amazingly fine sieve of natural selection.

The relationship between genetics and evolution extends to our own particular field, medical genetics. Our evolutionary past explains many facets of the allele structure of human populations; for example, the high prevalence of seemingly deleterious alleles responsible for diseases such as G6PD deficiency and sickle cell disease. Recognition and elucidation of genetic disorders such as microcephaly ${ }^{2,3}$ and language disorders ${ }^{4} \mathrm{can}$, in turn, inform the field of evolutionary biology. Medicine now stands on the brink of a new era, one driven by how the knowledge of one's genotype will affect treatment. Darwin would have been gratified that the solution to his most stubborn problem, that of inheritance, would not only cement his theory but benefit human health. Parenthetically, there is an intensely personal link between medical genetics and Darwin's life in that Charles Waring, his and Emma's last child, likely had Trisomy $21 .{ }^{5}$

There is an appropriate and growing emphasis on genetic education in medical school. This facet of a medical student's training needs to be coupled with evolutionary instruction so that students understand not only the "what's" of the human organism, but also the "why's". For it is predictable that when students begin their questions with "why," the answer is usu- 


\section{Editorial}

ally going to end up involving evolutionary biology. Whether it is why $80 \%$ of Americans suffer back pain during their lives, why we suffer from impacted wisdom teeth, or why we have an appendix whose only seeming purpose is to keep surgeons gainfully employed, the answer is only understandable in terms of evolution. Theodore Dhobsky's insight ${ }^{6}$ that "nothing makes sense in biology except in terms of evolution" will literally be a matter of life and death when we experience the emergence of the next influenza pandemic.

So let us celebrate the birth of a gentle man, 198 years ago on February $12^{\text {th }}$, who in ways deeply distressing him, not only changed science but also fundamentally changed the manner in which humans see themselves. Darwin's theory has gone from strength to strength; it is a privilege that our field is both the major buttress of evolutionary theory and its intellectual heir. Happy birthday to Charles Darwin ... the intellectual common ancestor of all geneticists.
James P. Evans, $M D, P h D$

Department of Genetics

University of North Carolina

Chapel Hill, North Carolina

\section{References}

1. Barnhart RK. The Barnhart concise dictionary of etymology: The origins of American English words. New York: Harper Collins Publishers, 1995.

2. Evans PD, Gilber SL, Mekel-Bobrov N, Vallender EJ, et al. Microcephalin, a gene regulating brain size, continues to evolve adaptively in humans. Science 2005;309: $1717-1720$.

3. Mekel-Bobrov N, Gilber SL, Evans PD, Vallender EJ, et al. Ongoing adaptive evolution of ASPM, a brain size determinant in Homo sapiens. Science 2005;309:1720-1722.

4. Enard W, Przeworski M, Fisher SE, Lai CS, et al. Molecular evolution of FOXP2, a gene involved in speech and language. Nature 2002;418:869-872.

5. Steensma DP. Down syndrome in Down House: trisomy 21, GATA1 mutations, and Charles Darwin. Blood 2005;105:2614-2616.

6. Theodosius Dobzhansky (1900-1975). Transcribed from Am Biol Teacher 1973;35: $125-129$.

\section{CALL FOR PAPERS}

Genetics IN Medicine encourages the submission of original research articles that focus on all facets of genetics in the realm of clinical medicine. We are particularly interested in emerging fields such as pharmacogenomics, research that crosses boundaries between disciplines, and evidence-based assessment of genetics and genetic tests. We strongly encourage submissions that highlight genetic aspects of diseases from specialties in which genetics has traditionally not been a major focus.

Please note that all submissions will be subject to peer review. For our complete Instructions for Authors, please visit the Genetics IN Medicine website at www.geneticsinmedicine.org.

\section{COVER ART}

We are always interested in artwork for our cover, particularly images that have both artistic and scientific merit or are aesthetically pleasing and informative in some way. Please submit cover art that you would like to be considered to gim@med.unc.edu. We look forward to yours contributions! 